\title{
Doppler Velocimetry evaluation in high-risk pregnancy for prediction of Preeclampsia
}

\author{
Rohini Singh ${ }^{1}$, Sudipa Mondal ${ }^{2}$, Manisha Bajaj ${ }^{3}$, Debasmita Mandal ${ }^{4}$ \\ ${ }^{1}$ Associate Professor, Department of Radiology, ESI-PGIMSR and ESIC Medical College, Joka, Kolkata, ${ }^{2}$ Post \\ Graduate Trainee, Department of Gynaecology and Obstetrics, ESI-PGIMSR \& ESIC Medical College, Joka, Kolkata, \\ ${ }^{3}$ Associate Professor, Department of Gynaecology and Obstetrics, ESI-PGIMSR \& ESIC Medical College, Joka, \\ Kolkata, ${ }^{4}$ Professor, Fetal Medicine Unit In Charge, IPGMER and SSKM Hospital, Kolkata
}

Background: The uterine and umbilical artery Doppler scan is a valuable tool for evaluation of utero-placental blood flow in pregnancy. They help in detecting uteroplacental insufficiency thus predicting preeclampsia and other effects of faulty placentation which increase the risk of adverse effects on both mother and fetus. Aims and Objective: This study aimed to evaluate and compare the uterine artery and umbilical artery Doppler indices in second and third trimester for prediction of preeclampsia in high-risk pregnancies. Materials and Methods: In this prospective observational study done over a years' time, 50 high-risk pregnant mothers were recruited and the Doppler scans were done at 21-25 weeks and 31-35 weeks. The necessary clinical observations were recorded throughout the antenatal period and the data analysis was done. Results: Majority (56\%) were in $20-29$ years range with mean age of $24 \pm 6.1$ years. Out of the 50 women, 21 had abnormal uterine artery Doppler and 12 had umbilical artery abnormality along with uterine derangement. Preeclampsia developed in 3 of them. The hypertensive disorders of pregnancy were diagnosed in 13 women, preeclampsia in 3, eclampsia in 1 and other HDPs in 9. The persistence of notch in uterine artery was observed in 7 women, of these 2 developed $\mathrm{PIH}$. Only one patient had uterine artery $\mathrm{PI}>1.45$ at 24 weeks who subsequently developed preeclampsia. Among 4 patients of preeclampsia and eclampsia, 3 had $2^{\text {nd }}$ trimester uterine and $3^{\text {rd }}$ trimester umbilical Doppler abnormalities and only 1 had normal doppler indices. In $2^{\text {nd }}$ trimester the sensitivity, specificity and PPV are higher for uterine artery PI as compared to umbilical artery PI. Hence, uterine artery doppler seems to be a better screening tool for early prediction of $\mathrm{PIH}$. The third trimester umbilical artery PI with higher specificity (96\%) and PPV $(50 \%)$ can diagnose preeclampsia better. One patient had absent diastolic flow and she developed preeclampsia and IUGR. The combined uterine and umbilical artery doppler is a better screening modality as it has a higher sensitivity $(75 \%)$ and NPV $(99.26 \%)$. Conclusion: The uterine and umbilical artery Doppler velocimetry are potential tools for uteroplacental surveillance of high-risk pregnancies which can identify patients at risk and help in taking timely action to prevent complications.
http://nepjol.info/index.php/AJMS DOI: 10.3126/ajms.v12i10.38390

E-ISSN: 2091-0576

P-ISSN: $2467-9100$

Copyright (c) 2021 Asian Journal of Medical Sciences

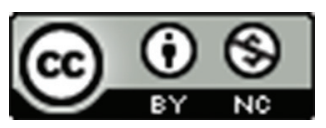

This work is licensed under a Creative Commons Attribution-NonCommercial 4.0 International License.

\section{INTRODUCTION}

India envisions achieving the Sustainable Development Goal (SDG) target of an MMR below 70 by $2030 .{ }^{1}$ Hypertensive disorders of pregnancy remain a major cause of maternal mortality in India and worldwide $(14 \%){ }^{2}$ Preeclampsia is a complex medical disorder occurring during pregnancy; worldwide, it accounts for more than
0.5 million foetal and neonatal deaths and more than 70000 maternal deaths every year. ${ }^{3}$ An early prediction of preeclampsia followed by better antenatal monitoring will result in optimally timed interventions which will avert complications and promise for better pregnancy outcomes.

The hypertensive disorders of pregnancy are prevalent in about $5-10 \%$ of antenatal women. ${ }^{4}$ The pathophysiology 
of preeclampsia entails shallow and faulty trophoblastic invasion of spiral arteries. This defective placentation leads to complications like haemorrhage, abruptio, preeclampsia, IUGR, still birth and others which may ultimately cause maternal and perinatal mortality. The Doppler assessment of the placental hemodynamics may have significant clues to its development and thus has potential to predict preeclampsia. ${ }^{5}$

Fitzgerald and Drumm ${ }^{6}$ and McCallum et al. ${ }^{7}$ were the first ones who evaluated Dopplers in obstetrics. The normal physiological vascular modification within the placenta and the foetus with redistribution of blood flow and alteration in circulating blood volume $e^{5}$ came under scanner with Doppler velocimetry.

Doppler parameters used in obstetrics to measure the blood flow in bilateral uterine and umbilical vessels are end diastolic velocity (EDV), peak systolic velocity (PSV), Pulsatality index (PI), resistance index (RI) and systolic to diastolic ratio (S/D ratio). ${ }^{8}$ Due to the presence of elasticity in the spiral arteries, a sharp systolic peak and forward flow in diastole up to 16 weeks of gestation is noticed as an early diastolic notch. Beyond this period, the notch disappears (18-23weeks) due to trophoblastic invasion of spiral arterioles. A high mean resistance greater than $95^{\text {th }}$ percentile for RI or PI, absent or reversed end diastolic flow denoting abnormal Doppler wave forms are indicators that the pregnancy may be at high risk of developing preeclampsia, foetal growth restriction, intrauterine death and placental abruption.

In this study we sought to determine the PSV, S/D ratio, $\mathrm{RI}$, and PI values in bilateral uterine and umbilical arteries among high-risk singleton pregnant women, and to calculate and compare the predictive value of the various doppler indices for early prediction of PIH.

\section{MATERIALS AND METHODS}

This observational prospective study carried out over a years' time in our tertiary care centre aimed at evaluating various Doppler parameters in $2^{\text {nd }}$ and $3^{\text {rd }}$ trimesters. After requisite clearance from institutional ethics committee, a total of 51 high-risk women with singleton pregnancy were enrolled after application of inclusion and exclusion criteria. Only one woman was lost to follow up as she didn't come for $3^{\text {rd }}$ trimester Doppler. Therefore, observation and analysis were done for the 50 women. A pragmatic sample size was calculated depending on the availability of logistics, resources and limited time frame.

\section{Inclusion criteria}

- History of hypertensive disorder of pregnancy, IUGR, still birth, abruptio in previous pregnancy, previous pregnancy loss, threatened abortion.

- Pre-existing medical disorders like Diabetes, Renal disease, Epilepsy, Autoimmune disease, Thrombophilia, chronic Hypertension.

- Extremes of age $(>35$ years or $<20$ years).

\section{Exclusion criteria}

Women with anomalous foetus, multiple gestations, irregular cycles, unknown dates, history of viral exanthematous fever, intake of drugs like antiepileptics, antipsychotics and anticoagulants.

The necessary clinical observations were made throughout the antenatal period of study participants. These observations and required demographic parameters were recorded in an organised structured proforma. Doppler measurements were done on these women at 21-25 weeks and 31-35 weeks. All were kept under closed monitoring till confinement and managed as per standard protocol.

The parameters studied were- Peak Systolic velocity (PSV), Resistive index (RI), Pulsatality index (PI), Systolic to diastolic ratio (S/D) in both arteries and presence of early diastolic notch in uterine artery. The value of PI, RI and S/ $\mathrm{D}>95^{\text {th }}$ percentile as per reference charts at the particular gestation was considered as abnormal. The normal Doppler parameters for gestational age were defined by using standard reference charts ${ }^{9}$ from Callen's ultrasonography in Obstetrics and Gynaecology (sixth edition, appendix D, pg 1204). In addition to this, persistence of early diastolic notch beyond 24 weeks, PI $>1.45$ in second trimester ${ }^{10}$ and $\mathrm{S} / \mathrm{D}$ ratio above 2.6 in third trimester in the uterine artery were also taken as abnormal. ${ }^{11}$ The technique for obtaining uterine artery and umbilical artery Doppler waveforms was as per ISUOG guidelines. ${ }^{12}$

Data was entered in Microsoft Excel Sheet. Descriptive analysis was done by calculating percentages, confidence interval, mean with SD, median and range. Appropriate statistical tests were applied as per the need of study. The statistical analysis was done by using the p-value $(<0.5)$ with confidence interval of $95 \%$.

In the second trimester comparative analysis of sensitivity, specificity, positive predictive value (PPV) and negative predictive value (NPV) of RI, PI of both uterine arteries and PI of umbilical artery was done. In the $3^{\text {rd }}$ trimester similar comparative analysis of all the three parameters (i.e., RI, PI and $\mathrm{S} / \mathrm{D}$ ) of both the umbilical and uterine artery was done.

\section{RESULTS}

In this longitudinal study on 50 high risk antenatal mothers, the majority (56\%) were in age range of $20-29$ years with 
mean age of $24 \pm 6.1$ years (range $18-43$ years). As per Modified Kuppuswamy Scale of socioeconomic status distribution majority of women belonged to Upper lower class $(60 \%)$. Most of them were primigravida $(40 \%)$.

The distribution of high-risk factors in these women was history of Gestational Diabetes Mellitus (GDM) (18\%), Pre-GDM (10\%), history of Gestational Hypertension (GHTN) (14\%), Chronic HTN (2\%), previous pregnancy loss $(26 \%)$, threatened abortion $(2 \%)$, history of GDM+ previous abortion $(26 \%)$, extremes of age i.e. $<20$ or $>35$ years $(8 \%)$, Pre-GDM+ Chronic HTN (2\%), Hypertensive disorder of pregnancy (HDP) + GDM (4\%), Chronic HTN+ GDM+ Previous Abortion (2\%), Pre-GDM+ previous pregnancy loss $(2 \%)$ and GHTN+ extremes of age $(2 \%)$. Of these 40 women had single high-risk factor and 10 had more than 1 high-risk factor. The commonest risk factors were GDM and previous pregnancy loss.

The mean gestational age at second and third trimester scan was 23.56 weeks and 32.55 weeks respectively. The placental location was anterior in $72 \%$, posterior in $26 \%$ and central in $2 \%$ on ultrasound examination. The mean gestational age at the time of delivery was 37.78 weeks.

The International Society for the Study of Hypertension in Pregnancy (ISSHP) says hypertensive disorder in pregnancy may be chronic (predating pregnancy or diagnosed before 20 weeks of pregnancy) or new onset (gestational hypertension, preeclampsia or eclampsia). Gestational hypertension is new onset hypertension after 20 weeks' gestation in the absence of proteinuria and without biochemical or haematological abnormalities whereas preeclampsia is classified as new onset hypertension after 20 weeks' gestation with proteinuria and/or evidence of maternal acute kidney injury, liver dysfunction, neurological features, haemolysis or thrombocytopenia, or foetal growth restriction. ${ }^{3}$

In our study, the total number of women diagnosed with hypertensive disorder of pregnancy were 13 and the rest 37 were normotensive. Among these13, preeclampsia was diagnosed in $3(6 \%)$, eclampsia in $1(2 \%)$ and other HDPs in $9(18 \%)$ which included gestational hypertension $(n=5)$ and chronic hypertension $(n=4)$. Other pregnancy outcomes were GDM in 23, IUGR in 14, SGA in 8, LBW in 8 , preterm in 10, PROM in 7, polyhydramnios in 6 and oligohydramnios in 5 and normal pregnancy outcome in $9(18 \%)$.

Out of the 50 women, 21 had abnormal uterine artery Doppler and 12 patients had both uterine and umbilical artery Doppler abnormalities. None of the pregnant women had sole abnormality of umbilical artery Doppler. Preeclampsia developed in 3 of them and IUGR foetus in 9 women.

The persistence of early diastolic notch in the uterine artery beyond 24 weeks was observed in 7 women, 5 had bilateral notches and 2 had unilateral notches. Out of these 2 women developed PIH, one with bilateral notch and the other with right side notch. Only one patient had uterine artery PI > 1.45 at 24 weeks who subsequently developed preeclampsia.

The analysis of the Doppler parameters of these 13 women who had hypertensive disorders of pregnancy was done retrospectively (Table 1). The values of PI and RI of both arteries and S/D of umbilical artery in most patients were higher than the reference $50^{\text {th }}$ centile value for that particular gestation as per Callens reference ${ }^{9}$ charts. Among 4 patients of preeclampsia and eclampsia, only $1 \mathrm{had}$ normal Doppler studies and rest 3 had $2^{\text {nd }}$ trimester uterine Doppler abnormality and $3^{\text {rd }}$ trimester umbilical Doppler abnormalities ( $>95$ centiles values for that particular gestation). Out of 5 patients of gestational hypertension, 3 had normal Doppler values, 1 had only uterine artery abnormality and the other had both uterine and umbilical abnormality. Rest 4 patients of chronic hypertension had normal Doppler parameters. Thus, as the pathology progresses, the Doppler values also worsen.

In $2^{\text {nd }}$ trimester the sensitivity, specificity and PPV are higher for mean uterine artery PI as compared to umbilical artery PI (Figure 1). Hence, uterine artery Doppler seems to be a better screening tool for early prediction of PIH. Although when we compare both the uterine arteries in our study, left uterine artery doppler is more sensitive, more specific, has higher PPV and NPV than right uterine artery doppler in prediction of preeclampsia. In $2^{\text {nd }}$ trimester the NPV is high and comparable for all doppler parameters of both uterine and umbilical arteries.

The third trimester uterine artery Doppler parameters have very low sensitivity, specificity, NPV and PPV compared to umbilical artery Doppler parameters (Figure 2). Sensitivity is higher for third trimester Umbilical artery PI, RI than the sensitivity of S/D ratio. But with higher specificity (96\%) and positive predictive value (50\%) PI can diagnose preeclampsia better. One patient had absent diastolic flow and she developed preeclampsia and IUGR. So, as a single parameter absent diastolic flow of umbilical artery Doppler can be important in managing preeclampsia and reducing perinatal mortality. The persistence of uterine artery notch in right and left artery has $25 \%$ sensitivity.

The sensitivity (75\%) and NPV (99.26\%) for predicting preeclampsia was better for Combined uterine artery and umbilical artery Doppler (test was considered as positive 


\begin{tabular}{|c|c|c|c|c|c|c|c|c|}
\hline & Mean Ut PSV* & Mean Ut PI & Mean Ut RI & Mean Ut S/D & Mean U PSV* & Mean U PI & Mean U RI & Mean U S/D \\
\hline 2nd Trimester & 55.48 & 0.90 & 0.52 & 2.17 & 41.89 & 1.02 & 0.65 & 2.93 \\
\hline 3rd Trimester & 61.23 & 0.85 & 0.48 & 2.02 & 46.8 & 1.01 & 0.61 & 2.47 \\
\hline
\end{tabular}

Ut=Uterine artery, PSV-peak systolic velocity, PI - Pulsatality index, RI - Resistive Index, S/D - Systolic/ Diastolic ratio, U=Umbilical artery, * =cm/s

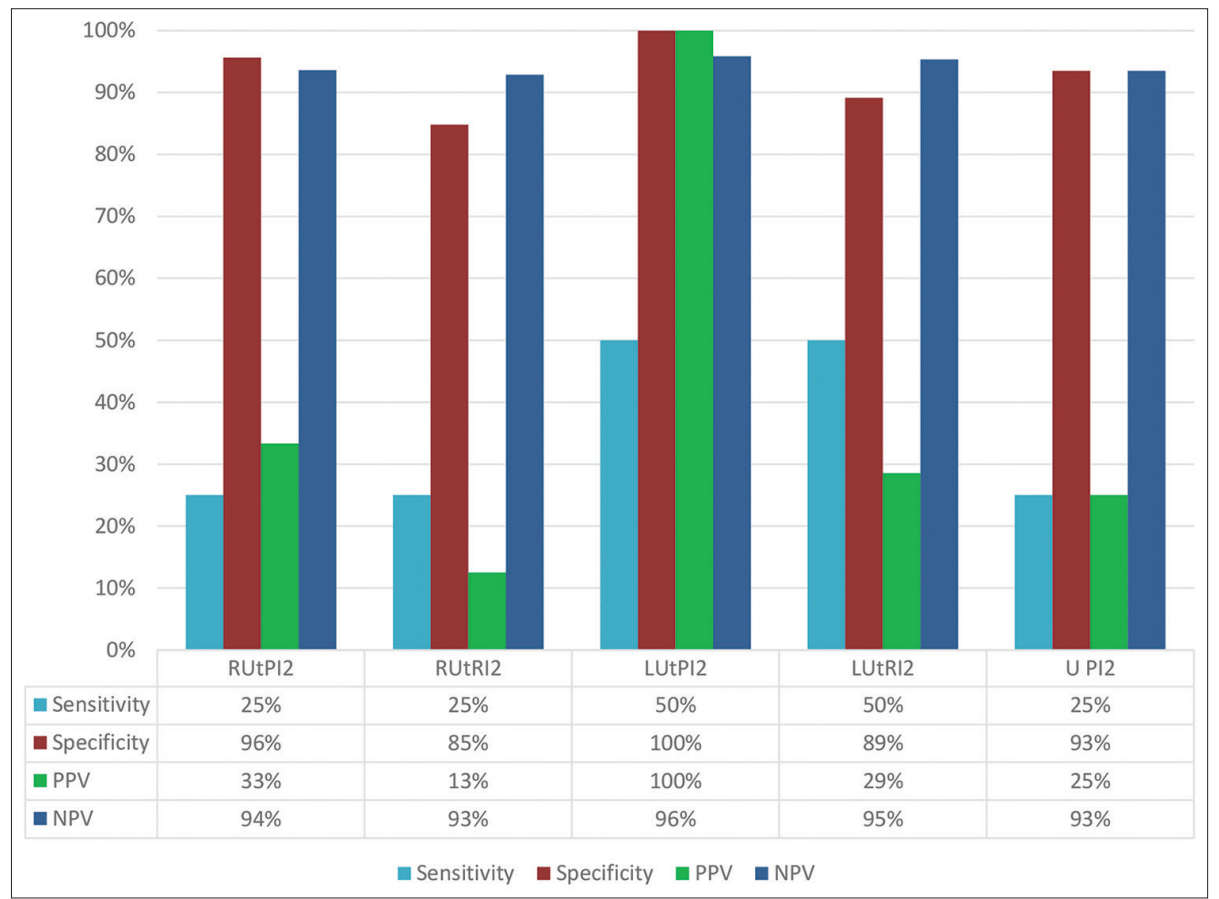

Figure 1: Prediction value of $2^{\text {nd }}$ trimester doppler for preeclampsia-eclampsia

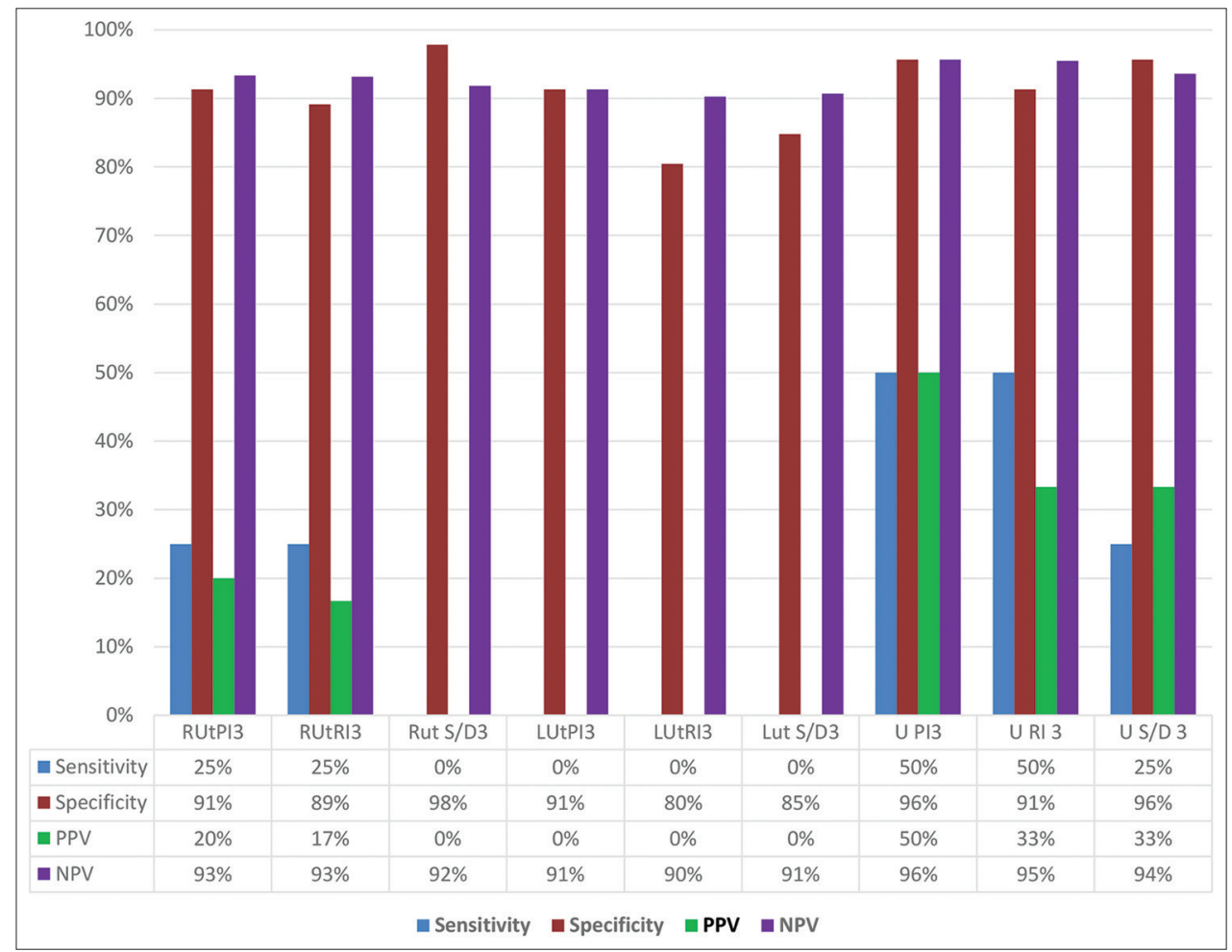

Figure 2: Prediction value of $3^{\text {rd }}$ trimester doppler in preeclampsia and eclampsia 
if any of the Doppler parameter was abnormal) compared to individual artery Doppler. The specificity was $93.75 \%$. It indicates combined uterine artery and umbilical artery Doppler can be used as a better screening modality as it has a higher sensitivity.

\section{DISCUSSION}

In this prospective study in tertiary care centre in one year of time we evaluated the Doppler indices of bilateral uterine arteries and umbilical artery between 21-25 weeks and at 31-35 weeks in 50 high-risk antenatal mothers and calculated their predictive values for preeclampsia. Although studies have been done in this field but interrogation of both arteries in both trimesters is less evaluated.

In this study most of the cases are between 20 to 29 years of age, similar to the T Nagar et al., ${ }^{13}$ study where $55 \%$ pregnant women were in age group of 21-25 years and $33 \%$ in $26-30$ years range.

All preeclampsia patients in our study population were primigravida; which is comparable to Khalid et al., ${ }^{14}$ study where $77.77 \%$ were primigravida. In control group of the same study $54.5 \%$ were primigravida.

The physiological change in vascular resistance of the blood flow takes a minimum of 9-10 weeks that's why we did second trimester scan between 21-25 weeks and repeated again at 31-35 weeks, the same protocol was followed by J Adekanmi. ${ }^{8}$ The mean gestational age was approximately $23^{\text {rd }}$ week for second trimester scan and 32-33 weeks for third trimester scan.

In our study all preeclamptic patients had anterior placenta whereas eclamptic patient had posterior placenta. Shumailazia ${ }^{15}$ stated anterior placental implantation is associated with an increased risk of pregnancy-induced hypertension, gestational diabetes mellitus, placental abruption, intrauterine growth retardation and intrauterine foetal death.

Eight percent patients developed Preeclampsia-Eclampsia in current study, which is similar to study reported by J Mayrink et al., which showed incidence of $7.5 \% .{ }^{16}$

In our study as well as in P R Desai ${ }^{17}$ study the umbilical artery Doppler PI, RI, S/D values decrease from second trimester to third trimester, importance of which has been explained by Olofsson et al. ${ }^{18}$ The mean uterine artery PI was higher in PIH than normal pregnancy outcome in both trimesters in our patients which explains the failure of physiological changes in uteroplacental flow leading to high risk of obstetrical complications. ${ }^{19}$ The mean umbilical artery PI, RI, S/D is slightly higher in PIH than normal pregnancy outcome in both trimesters which indicates failure of increase diastolic flow; this is also explained by Gudmundsson S and Marshal K. ${ }^{20}$

Out of 50 pregnant women, $21(42 \%)$ had abnormal uterine artery Doppler and among them $12(24 \%)$ had umbilical artery abnormality as well. None of the patients had sole umbilical artery Doppler abnormality. In T Nagar study ${ }^{13}$ on 500 high risk patients, $110(22 \%)$ had abnormal Doppler, $70(14 \%)$ patients had abnormal uterine artery Doppler and $50(10 \%)$ patients had abnormal umbilical artery Doppler indices.10 (2\%) patients had both uterine and umbilical artery Doppler abnormalities. Mirza et al., ${ }^{21}$ did a retrospective study on 268 women. Abnormal umbilical artery Doppler was reported in $57(21.26 \%)$ women, of those $8(14 \%)$ developed Preeclampsia. He concluded that patients with abnormal umbilical artery Doppler have more risk of developing preeclampsia. In our study of 50 high risk women, $12(24 \%)$ had abnormal umbilical artery Doppler derangement and $3(6 \%)$ developed preeclampsia.

\begin{tabular}{|c|c|c|c|}
\hline $\begin{array}{l}\text { Uterine artery } \\
\text { Doppler }\end{array}$ & $\begin{array}{l}\text { Abnormal } \\
\text { results }\end{array}$ & $\begin{array}{c}\text { GA } \\
\text { weeks }\end{array}$ & $\begin{array}{l}\text { Sensitivity (\%) } \\
\text { of predicting } \\
\text { Preeclampsia }\end{array}$ \\
\hline $\begin{array}{l}\text { Torres C \& } \\
\text { Raynor B } \\
\text { et al. } .^{22}\end{array}$ & $\begin{array}{l}\mathrm{Pl}>1.0, \mathrm{Rl}>.57 \\
\mathrm{~S} / \mathrm{D}>2.6, \text { notch }\end{array}$ & $\begin{array}{c}2^{\text {nd }} \\
\text { trimester }\end{array}$ & 25 \\
\hline Kurdi et al. ${ }^{23}$ & $\begin{array}{l}\mathrm{RI}>0.55 \\
\& \text { bilateral } \\
\text { notches, } \\
\text { Bilateral } \\
\text { notches \& } \\
\mathrm{RI}>0.55 \\
\text { or unilateral } \\
\text { notch \& } \\
\mathrm{RI}>0.65 \\
\text { or mean } \\
\mathrm{RI}>0.7\end{array}$ & $19-21$ & 62 \\
\hline Frusca et al. ${ }^{24}$ & Mean $\mathrm{RI}>0.58$ & $20 \& 24$ & 50 \\
\hline Dhar et al. ${ }^{25}$ & $\begin{array}{l}\mathrm{PI}>95^{\text {th }} \\
\text { percentile }\end{array}$ & 23-24 & 66.66 \\
\hline $\begin{array}{l}\text { Albaiges } \\
\text { et al. }^{26}\end{array}$ & Mean $\mathrm{PI}>95^{\text {th }}$ & 23 & 35 \\
\hline \multirow[t]{3}{*}{ T Nagar et al. ${ }^{13}$} & $\mathrm{RI}$ & $26-30$ & 40 \\
\hline & S/D ratio & & 60 \\
\hline & Notch & & 60 \\
\hline \multirow[t]{5}{*}{ Current study } & $\begin{array}{l}\mathrm{Pl}>95^{\text {th }} \\
\text { percentile of ref } \\
\text { value }\end{array}$ & $21-25$ & $25(\mathrm{Rt} U t)$ \\
\hline & & & 50 (Lt Ut) \\
\hline & $\begin{array}{l}\mathrm{Rl}>95^{\text {th }} \\
\text { percentile of ref } \\
\text { value }\end{array}$ & & 25(Rt ut) \\
\hline & & & 50 ( Lt ut) \\
\hline & Notch & & 25(Rt ut) \\
\hline
\end{tabular}


The uterine artery PI above 1.45 was observed in 3 patients in second trimester ultrasound and all the patients had adverse pregnancy outcome. One developed Preeclampsia (with poor Apgar and 4 days NICU stay), 1 IUGR, other 1 developed foetal distress; which is in agreement with M. Bararti et al., ${ }^{10}$ who explained the importance of uterine artery PI above 1.45 between 19-22 weeks of gestation (Table 2).

The sensitivity and specificity of doppler indices for predicting PIH in our study was similar to study by T Nagar et al. ${ }^{13}$ The umbilical artery RI had sensitivity, specificity, PPV and NPV of $40 \%, 96.84 \%, 40 \%$ and $96.84 \%$ respectively. The same for S/D ratio in their study was $48 \%, 93.68 \%$, $25 \%$ and $96.74 \%$ respectively.

\section{CONCLUSION}

In this prospective study we found that the uterine artery and umbilical artery Doppler velocimetry is a primary tool for uteroplacental and fetoplacental surveillance of pregnancies especially the high-risk ones.

The sensitivity, specificity and PPV are higher for mean uterine artery PI compared to umbilical artery PI in $2^{\text {nd }}$ trimester. Hence uterine artery doppler seems to be a better screening tool for early prediction of PIH in second trimester. The left uterine artery Doppler appears to be more sensitive and specific than right uterine artery Doppler in prediction of preeclampsia although more studies are needed to confirm so.

The abnormalities in umbilical artery PI develop frequently in Preeclampsia in third trimester. The absent end diastolic flow is important predictor of adverse neonatal outcome and helps in timely intervention to reduce perinatal complications. However, the combination of uterine artery and umbilical artery Doppler is the best predictor for Preeclampsia.

\section{Take home message}

The evaluation of uterine artery and umbilical Doppler indices helps to take timely action and plan the treatment. Therefore, regular uterine artery and umbilical artery Doppler surveillance may be employed in hospitals to identify patients at risk of developing obstetrical complications and poor foetal outcome. It was a time restricted study and the study population was not very large. More prospective studies with larger study population are required to evaluate further for robust data and strong recommendations.

\section{ACKNOWLEDGEMENT}

The authors take the opportunity to thank Department of Obstetrics and Gynaecology and Radiology, ESI-PGIMSR
\& ESIC-MC, Joka for their whole hearted support for this study.

\section{REFERENCES}

1. How many lives are at stake? Assessing 2030 sustainable development goal trajectories for maternal and child health, John W McArthur, Krista Rasmussen, Gavin Yamey, BMJ 2018;360:k373

https://doi.org/10.1136/bmj.k373

2. Global causes of maternal death: a WHO systematic analysis: Lale Say, Doris Chou, Alison Gemmill, ÖzgeTunçalp,Ann-Beth Moller, Jane Daniels, et al.The Lancet Global Health, Volume 2, Issue 6, e323 - e333, JUNE 01, 2014

https://doi.org/10.1016/S2214-109X(14)70227-X

3. Hypertensive Disorders of Pregnancy: ISSHP Classification, Diagnosis, and Management Recommendations for International Practice Mark A. Brown, Laura A. Magee, Louise C. Kenny, S. Ananth Karumanchi, Fergus P McCarthy, Shigeru Saito, David R. Hall, Charlotte E. Warren, Gloria Adoyi and Salisulshaku on behalf of the International Society for the Study of Hypertension in Pregnancy (ISSHP) Hypertension. 2018;72:24-4 https://doi.org/10.1161/HYPERTENSIONAHA.117.10803

4. Hypertensive Disorders of Pregnancy and Future Maternal Cardiovascular Risk, Wendy Ying, Janet M. Catov, and Pamela Ouyang, Journal of the American Heart Association. 2018; 7:e009382.

https://doi.org/10.1161/JAHA.118.009382

5. Montague I and Dubbins PA. Clinical applications of Doppler ultrasound in obstetrics. In: Allan P, Dubbins PA, Norman McDicken W, Pozniak MA, editors. Clinical Doppler Ultrasound. 2 nd ed. Philadelphia, USA: Churchill Livingstone Elsevier; 2006. p. 315.

https://doi.org/10.1016/B978-0-443-10116-8.50018-X

6. FitzGerald DE and Drumm JE. Non-invasive measurement of human fetal circulation using ultrasound: a new method. $\mathrm{Br}$ Med J. 1977;2(6100):1450-1451.

https://doi.org/10.1136/bmj.2.6100.1450

7. McCallum WD, Olson RF, Daigle RE and Baker DW. Real time analysis of Doppler signals obtained from the fetoplacental circulation. Ultrasound Med. 1977; 3B: 1361-1364.

8. Adekanmi AJ, Roberts A, Adeyinka AO, Umeh EO, Anor F, Odo JC, et al. Normal second and third trimester uterine and umbilical doppler indices among healthy singleton gestation Nigerian women. West African J of Radiology. 2017; 24: 1-7. https://doi.org/10.4103/1115-3474.198078

9. Merz E (ed): Ultrasonography in Obstetrics and Gynecology. Stuttgart, Thieme, 2005, pp 469-480, 613, 614

10. Barati M, Shahbazian N, Ahmadi L and Masihi S. Diagnostic evaluation of uterine artery Doppler sonography for the prediction of adverse pregnancy outcomes. J Res Med Sci. 2014; 19(6):515-519.

11. Yang CS. Doppler flow velocity waveform of the maternal uterine artery and fetal umbilical artery in normal pregnancy and pregnancy induced hypertension. Zhonghua Fu Chan KeZaZhi 1989; 24(5): 261-264.

12. ISUOG Practice Guidelines: use of Doppler ultrasonography in obstetrics: Ultrasound Obstet Gynecol. 2013; 41: 233-239. https://doi.org/10.1002/uog.12371

13. Nagar T, Sharma D, Choudhary M, Khoiwal S, Nagar RP and Pandita A. The Role of Uterine and Umbilical Arterial Doppler in High-risk Pregnancy: A Prospective Observational Study from 
India. Clin Med Insights Reprod Health. 2015; 9:1-5.

https://doi.org/10.4137/CMRH.S24048.

14. Khalid M, Wahab S, Kumar V, Khalid S, Haroon S and Sabzposh NA. Doppler indices in prediction of fetal outcome in hypertensive pregnant women. NJOG.2011; 6(1):28-34. https://www.nepjol.info/index.php/NJOG/article/view/5249

15. Zia S. Placental location and pregnancy outcome. J Turk Ger Gynecol Assoc. 2013; 14(4):190-193. https://doi:10.5152/jtgga.2013.92609

16. Mayrink J, Souza RT, Feitosa FE, Rocha Filho EA, Leite DF Vettorazzi J, et al. Incidence and risk factors for Preeclampsia in a cohort of healthy nulliparous pregnant women: a nested casecontrol study. Sci Rep. Article 9, 9517 (2019).

https://doi:10.1038/s41598-019-46011-3

17. Desai PR, Dahilkar RP and Tiwale SM. Umbilical artery doppler indices in IUGR pregnancies. Int J Basic Appl Physiol. 2014; 3(1): 40-48.

18. Olofsson $P$, Lingman $G$, Marsal $K$ and Sjoberg NO. Fetal blood flow in diabetic pregnancy. J Perinat Med.1987; 15:545-553. https://doi.org/10.1515/jpme.1987.15.6.545

19. Papageorghiou AT, Yu CKH, Bindra R, Pandis G and Nicolaides KH Multicenter screening for pre-eclampsia and fetal growth restriction by transvaginal uterine artery Doppler at 23 weeks of gestation. Ultrasound Obstet Gynecol. 2001; 18(5):441-449. https://doi.org/10.1046/j.0960-7692.2001.00572.x

20. Gudmundsson S and Marshal K. Ultrasound Doppler evaluation of uteroplacental and fetoplacental circulation in pre- eclampsia. Arch Gynaecol Obstet. 1988; 243 (4):199-206.
https://doi.org/10.1007/BF00932268

21. Mirza FG, Strohsnitter WC, Rivera J and Gyamfi-Bannerman C. Intrauterine growth restriction with abnormal umbilical artery Dopplers: a harbinger for preeclampsia? J Matern Fetal Neonatal Med. 2012; 25(12):2658-2661.

https://doi.org/10.3109/14767058.2012.704443

22. Torres $C$ and Raynor B. Uterine artery score and adverse pregnancy outcomes in a low- risk population. Am J Obstet Gynecol. 2005; 193: s 167.

https://doi.org/10.1016/j.ajog.2005.10.670

23. Kurdi W, Campbell S, Aquilina J, England P and Harrington K. The role of color Doppler imaging of the uterine arteries at 20 weeks' gestation in stratifying antenatal care. Ultrasound Obstet Gynecol. 1998;12(5):339-345 https://doi.org/10.1046/j.1469-0705.1998.12050339.x

24. Frusca T, Soregaroli M, Valcamonico A, Guandalini $F$ and Danti L. Doppler velocimetry of the uterine arteries in nulliparous women. Early Hum Dev. 1997; 48: 177-185. https://doi.org/10.1016/S0378-3782(96)01854-3

25. Dhar A and Dhar IK. A Value of PI of uterine artery at 2324 weeks in the prediction of adverse pregnancy outcome et al. Int J Reprod Contracept Obstet Gynecol. 2017; 6(12):5435-5439. https://doi.org/10.18203/2320-1770.ijrcog20175256

26. Albaiges G, Missfelder-Lobos $H$, Lees $C$, Parra $M$ and Nicolaides $\mathrm{KH}$. One-stage screening for pregnancy complications by color Doppler assessment of the uterine arteries at 23 weeks' gestation. Obstet Gynecol. 2000; 96: 559-564. https://doi.org/10.1016/S0029-7844(00)00946-7

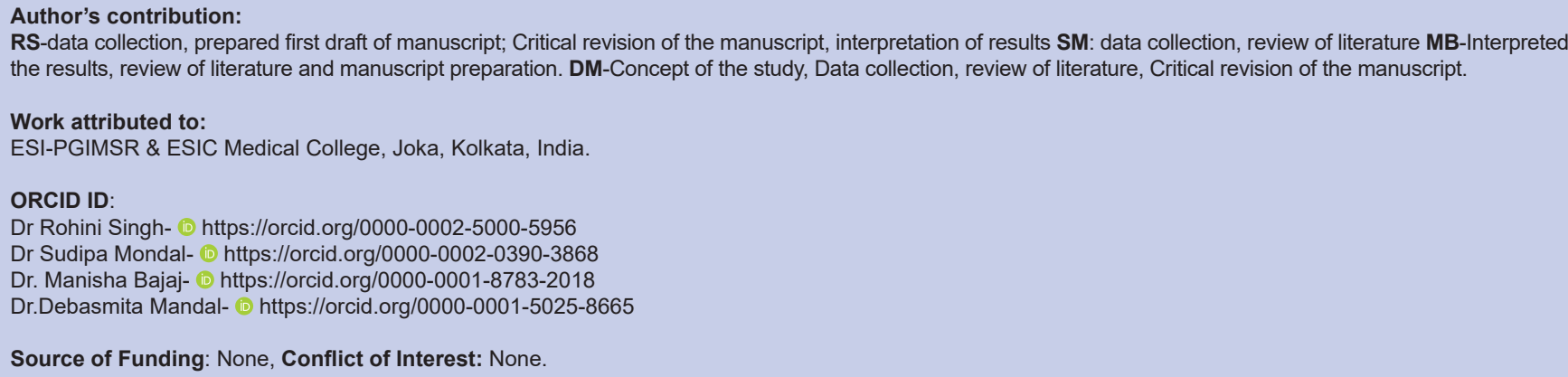

